\title{
Utilization status of sexual and reproductive health services among high school students in assosa zone; western ethiopia, 2021.
}

Hunduma Dina Hambisa ( $\nabla$ hunde4mother@gmail.com )

Assosa University

Simachew Kassa

Bahir Dar University

Shumiye Shiferaw

Bahir Dar University

Research

Keywords: Youths, Students, Utilization, sexual and Reproductive health services, Ethiopia

Posted Date: November 23rd, 2021

DOI: https://doi.org/10.21203/rs.3.rs-1075288/v1

License: (a) (i) This work is licensed under a Creative Commons Attribution 4.0 International License. Read Full License 


\section{Abstract}

Introduction: - Sexual and reproductive health service is critical for youths; because it does not only set the stage for health beyond the reproductive years; it also affects the health of the next generation. Youth is one of life's most fascinating and complex life stages and accompanied by special sexual and reproductive health needs.

Objective: - This study was aimed to determine; utilization status of sexual and reproductive health services and associated factors among high school students in Assosa Zone Western Ethiopia.

Methods: - School-based quantitative cross sectional study was carried out among all students from systematically selected in high school of Assosa Zone. Total of 400 samples were proportionally allocated for the stratum and eligible students in were interviewed. Pretested structured questionnaires were employed to obtain quantitative data. The collected data was interred into Epidata version 3.1 and analysed using SPSS version 25 software.

Results: - Over all utilization of sexual and reproductive health services by youth students was $32 \%$ in the past six months. Counseling services was the major (33.6\%) service utilized and Private clinic was the major 73\% place of sexual and reproductive health service utilized. Having pocket money [95 \% Cl (AOR=2.81 $(2.35,5.09)]$, being sexually active $[95 \% \mathrm{Cl}(\mathrm{AOR}=1.82(1.25,3.26)]$, parental discussion $[95 \% \mathrm{Cl}(\mathrm{AOR}=2.78(1.59,4.67)]$, peer education was also significantly associated with utilization of sexual and reproductive health services.

Conclusions: - Over all utilization of sexual and reproductive health service among youth students in the past six months was $32 \%$. To improve youth's sexual and reproductive health service utilization; increasing accessibility, awareness creation at all levels as well as making the service confidential should be interventional areas.

\subsection{Introduction}

Youths begin to define and clarify their sexual values and often begin to experiment with sexual behaviour. These typical characteristics of adolescents lead to an increased risk of various sexual and reproductive health problems, particularly in sub-Saharan Africa including Ethiopia(1).

Young people from sub-Saharan Africa are more at risk of sexual and reproductive health problems than young people around the world(2). Each year, an estimated 1.7 million adolescents lose their lives prematurely due to preventable or treatable problems such as accidents, violence, pregnancy complications and other illnesses. For these reasons, adolescent sexual and reproductive health (YSRH) is becoming an increasingly important part of global health strategy(3).

Evidence suggests that investing in the health of young people is critical to a country's socio-economic development(4).Sexual and reproductive health service is a crucial, as it is not only creates the conditions for health beyond the reproductive years; it also affects the health of the next generation(5).Youth Sexual and reproductive health services are; access to SRH education, information and counselling contraceptives ,Abortion services and treatments of STIs, that all people can safely reach services provided in an atmosphere 
of trust and confidentiality to make every contact a milestone visit. This makes it possible to successfully win, support and retain the young customers(6).Sexual and reproductive health service is fundamental human rights to which adolescents and youths are entitled, and care providers and planners should understand this adolescent's right to access SRH information and services in order to make an informed decision(7).Young people often do not have access to information about sexual and reproductive health services and how to use health services. Worldwide, around $45 \%$ of all new infections with the human immunodeficiency virus (HIV) occurred in people aged 1524 years. In Africa, an estimated 1.7 million young people have been exposed to many reproductive health problems, and $60 \%$ of all new HIV infections occur in adolescents 1,519 years and older $(8,9)$. In Ethiopia alone, there are about 87,000 young population living with HIV and 8,700 new cases among young population across the country(10).A study by the Ethiopian Ministry of Health found that $17 \%$ of young women and $14 \%$ of young men aged 20 to 24 were sexually active by the age of fifteen years. The risks of neglecting YSRH are great; painful or damaging transition to adulthood can result in a lifetime of ill effects. Girls exposed to early pregnancy / motherhood can pose a physical risk and the potential can affect educational achievement and economic growth $(11,12)$.

The incidence of premature births varies greatly from region to region. Recently it has ranged from $9.6 \%$ in Addis Ababa to $59 \%$ in Benishangul-Gumuz(13).Indeed, adolescent pregnancy is dangerous, with serious long-term and wide-ranging consequences from health complications to broader economic concerns(14).

Prevalence of sexually transmitting infections among Gonder university students was found to be $18.20 \%$ North West Ethiopia. STIs can result in long life disabilities and burdens on countries economy by increasing loss of youth lives(15).According to a study in northeast Ethiopia, 23.5 unwanted pregnancies are a leading cause of unsafe abortions. Unsafe abortions are an important contributor to maternal mortality, with an estimated 22 million cases annually and between $4.7-13.2 \%$ of maternal deaths globally (16).The study conducted in North west Ethiopia identifies that knowledge status of liberalized safe abortion among Debra Markos female students' is $41.2 \%$ only. More over Low knowledge status of abortion legality enforces the students to attempt unsafe abortion and increase mortality rates(17). Thirty four (83.9\%) adolescents of 15 to 19 years and 46 (46\%) 20 to 24 years old women underwent unsafe abortion(18). In Benishangul-Gumuz region, health care systems is weak and school based education and information provision of youth health was fragmented with the poor coordination between health and education sectors(19).Efforts have been made to address youth Sexual and reproductive health service problems at different levels. Ethiopia ministry of health $(\mathrm{FMOH})$ launches several strategies to promote adolescents and youth reproductive health services National Adolescent and youth Reproductive Health Strategy 2007-2015 and, Standards on YFRH Services and tools for planning, implementation and monitoring of the health care system $(6,20)$.Irrespective of those above efforts utilization of youths SRH service is $21.21 \%$ in Nekemte town high school youth students which was below the target of Ethiopian federal ministry of AYRH strategies developed in 2016 (21) and also literatures on youth students utilization of SRH services was rare in Ethiopia.

Throughout sub-Saharan Africa countries level of SRH service is different. In Ghana 55.8\% the youth had utilized at least one or more of a sexual and reproductive health service in life time(22). Malawi contraceptive Unmet Need was19\% among 15-24 years in 2014 (23).Even across the regions in Ethiopian utilization of YSRH services has great variation, 32.1\% in Bahirdar (24),to 69.1.1\% in Mekelle town, Utilization of Youths 
sexual reproductive health services not only differs from one country to other, but also varies within a single country(25-27).

Some local studies that have been carried out in Ethiopia show that young people pocket a lot, residences, family life, parents' educational and economic level, unfavourable attitude and negative perceptions of parents towards health behaviour of young people, age and gender differences, marital status, death of the family, certain social cultures, taboos and other socio-economic factors have a direct and indirect impact on the use of YSRH services $(25,28)$.

Many studies have attempted to identify factors contributing to poor YSRH service. These are: - source of information, knowledge about SRH services, sexual behaviours, self / partner trust, embarrassment, attitudes towards the SRH service, discussions about sexual and reproductive health with their family members have a significant influence on the level of SRH services for adolescents $(21,24,27)$. History of sexual practices, exposure to $\mathrm{SRH}$ problems were, peer education and youth preference of place, time and Health care providers $(28,29)$.

In Ethiopia, parents were often ignorant, preferring their children to learn from teachers, peers and healthcare professionals; Parents 'discussion of sexual and reproductive health issues in order to improve adolescents' knowledge is also significantly linked; The parents' discussion on issues of sexual and reproductive health in order to improve the knowledge of young people is also significantly linked(26, 30).

Reproductive health services can play an important role in both health promotion and prevention. However; According to the study carried out in South Africa, the existing health services in various countries are not fully accessible, affordable and acceptable for young people(31).

Obstacles to the use and access to sexual and reproductive health $(\mathrm{SRH})$ services for young people are: Lack of well-trained health care providers, costs of services and goods, service privacy, absence of YFS, inconvenient operating hours of health facilities, Low accessibility to SRH services are the main drivers of low use of SRH services, such as the studies conducted in Awabel District, Northwest Ethiopia and Woreta City, Northwest Ethiopia, and attitudes of health professionals towards AYSRH services $(30,32)$

\subsection{Objective Of The Study}

\subsection{General objectives}

To assess utilization and factors associated with sexual and reproductive health services among high school students in Assosa western Ethiopia, 2020.

\subsection{Specific objectives}

- To determine utilization of sexual and reproductive health service among in high school youth students in Assosa western Ethiopia/2020.

- To identify factors associated with utilization of sexual and reproductive health service among in high school youth students in Assosa western Ethiopia, 2020. 


\section{Methods}

\subsection{Study area}

This study was carried out in the Assosa Zone in western Ethiopia. This zone has a city administration and a total population of 89,232 , of which 44,906 men and 44,326 women, and is located $670 \mathrm{~km}$ southwest of the Ethiopian capital Addis Ababa. According to reports from the Benishangul Gumuz Zone Education Bureau, there were 16 high schools in the Assosa Zone, with an estimated number of 50 students per class. In terms of health facilities in the Assosa region, there were 1 general hospital, 2 health canters, 6 private clinics and 5 health stations(33).

\subsection{Study periods}

The study was conducted from March 2-13/2020 among high students in high schools in Assosa Zone western Ethiopia.

\subsection{Study Design}

School-based quantitative cross sectional study was carried out among selected students in high school of Assosa Zone administration western Ethiopia.

\subsection{Population}

\subsubsection{Source population}

Students In high schools found in Assosa zone administration registered for 2019/2020 academic year.

\subsubsection{Study population}

All students from randomly selected sections

\subsubsection{Study participants}

Eligible students from randomly selected students of the high schools

\subsection{Inclusion and exclusion criteria}

\subsubsection{Inclusion criteria}

All students attending high school education during study period were included.

\subsubsection{Exclusion criteria}

Students those declare illness during data collection period were excluded

\subsection{Sample size determination}

The required sample size was determined by using single population proportion formula by considering the following assumptions- $\mathrm{P}=38.5 \%$ (as an estimated prevalence of sexual and reproductive health service utilization in the past one year among high school youths taken from the study conducted in Hadiya 
Zone(34) southern nation and nationalities and peoples State of Ethiopia. By considering 95\% confidence level

$$
\begin{aligned}
& \mathrm{n}=\frac{\left[(Z \alpha / 2)^{2}\right] 0 .(1-p)}{[d]^{2}} \\
& =\frac{\left[(1.96)^{2}\right] 0.385(1-0.385)}{[0.05]^{2}} \\
& =\frac{0.90959484}{0.0025}
\end{aligned}
$$

$=363.8$

$=364$

By adding $10 \%$ of non-response rate the final sample size was 400

\subsection{Sampling techniques}

After stratifying eight high schools into grades (9th, 10 th, $11^{\text {th, }} 12$ th $)$ the total of 400 samples were allocated proportional to the size of the student they have. Grades were heterogeneous and students in the same grades were homogeneous; by considering that until allocated sample were gained the required students selected from each stratum by lottery methods and self-administered questionnaires were distributed for eligible students

\subsection{Operational definitions}

Use of Sexual and Reproductive Health Services: - Was assessed based on student practice, one or more components of the SRH service (contraception, treatments for STIs, VCT of HIV, abortion service, SRH information education and counselling, and pregnancy test for the last six months $(21,30)$.

\section{Youth students}

-students those in between 15-24 years age group and enrolled in high schools.

\section{Sexually active}

-having a previous history of sexual intercourse.

Knowledgeable: -Students' knowledge of sexual reproductive health was determined by the average score of six knowledge questions created by true or false dictation answers. Teens who scored lower than the mean were inexperienced and those who were knowledgeable were scored higher than or equal to the mean of the knowledge questions $(21,30,34)$.

Favourable attitude: -The attitudes of students to sexual and reproductive health were determined using six attitude questions, which were created with a Liker-Scoring-System. Adolescents with positive attitudes 
scored greater than or equal to the average liker score points, and those who scored less than the average liker score on the attitudes questions had an unfavourable attitude $(21,28,35)$.

\subsection{Data collection instruments}

For data collection, a structured, self-administered questionnaire was adopted in English after reviewing various literatures and modified depending on the local situation and research objective. It was first developed in English and then translated into Amharic and translated back into English to check its consistency. The questionnaires contain questions about demographic and socio-economic factors, individual factors, health institutions and family-related factors.

\section{Data collectors}

Two Supervisors with back grounds of MSC maternity and reproductive health and four data collectors of two BSC nurses two BSC midwifes were trained to assist students and monitor overall data collection process. In order to identify the clarity of questions and their sensitiveness, pre-testing of the instrument will be done on $5 \%$ of the students among non-selected students. During the pre-test; discussion was held with the students on any problem they encountered during filling of the questionnaire.

\subsection{Data quality management}

Data quality was assured through careful design of the questionnaire. Data collectors and supervisors were trained in one day about the purpose of the study, the questionnaire in detail, the data collection procedure and the rights of study participants. Pre-test was done prior to the actual data collection. The collected data were checked for completeness and consistency after each day of data collection by holding a meeting with the data collectors.

\subsection{Data processing and analysis}

Data was coded, cleaned and entered into Epidata version 3.1 and analysed by SPSS Version 25 for the analysis and collinearity check by SPSS. Variable with P-value $<=0.25$ in bivariate logistic analysis were transferred into multivariate logistic analysis .Frequency, percentages, proportions, odds ratios, were computed. Adjusted odds ratios with the $95 \%$ confidence interval and $p$-value of less than 0.05 were considered to be significant

\subsection{Ethical Consideration}

Ethical approval was obtained from Bahirdar University, institutional review board, Research ethics and letter of permission was obtained from Benishangul Gumuz Regional educational bureau. The purpose of the study was explained to youth students and a written informed consent was obtained from the participants. Confidentiality of information was maintained by omitting any personal identifier from the questionnaire. 


\section{Results}

\section{Socio demographic Characteristics of participants}

A total of 375 students were participated in the study which makes response rate of $94 \%$. One hundred sixty eight (44.8\%) females and (55.20\%) were males. Over all participants age fall in age 20-24 one hundred ninety seven (52.5\%). Three hundred thirteen (83.5\%) single and one hundred fourteen were Oromo $(30.4 \%)$ followed by Amhara (25.3\%) and the three smallest ethnic groups were Mao and Komo and Tigre(7.2\%) grouped under other by ethnicity. Based on religious; majority of them (31.54\%) were Orthodox religious followers. 
Table 1

Socio-demographic characters of high school students in Assosa zone western Ethiopia, 2021.

\begin{tabular}{|c|c|c|}
\hline \multicolumn{2}{|l|}{ Characteristics ( $n=375)$} & \multirow{2}{*}{$\begin{array}{l}\text { Frequency and percentages } \\
178(47.5)\end{array}$} \\
\hline Age in years & $15-19$ & \\
\hline & $20-24$ & 197(52.5) \\
\hline \multirow[t]{2}{*}{ Sex } & Male & $207(55.2)$ \\
\hline & Female & $168(44.8)$ \\
\hline \multirow[t]{2}{*}{ Residence } & rural & $86(23 \%)$ \\
\hline & urban & $289(77 \%)$ \\
\hline \multirow[t]{5}{*}{ Religious } & orthodox & 118(31.5) \\
\hline & Catholic & $52(13.86)$ \\
\hline & Protestant & $75(20 \%)$ \\
\hline & Muslim & $111(29.6 \%)$ \\
\hline & Other * & $19(5 \%)$ \\
\hline \multirow[t]{4}{*}{ Students' level of education } & 9th & $186(49.6 \%)$ \\
\hline & 10th & $137(36.5)$ \\
\hline & 11th & $27(7.2 \%)$ \\
\hline & 12th & $25(6.7 \%)$ \\
\hline \multirow[t]{7}{*}{ Ethnicity } & Oromo & $114(30.4)$ \\
\hline & Amhara & $95(25.3 \%)$ \\
\hline & Gurage & $25(6.7 \%)$ \\
\hline & Berta & $55(14.7 \%)$ \\
\hline & Shinesha & $28(7.5 \%)$ \\
\hline & Gumuz & $31(8.3 \%)$ \\
\hline & Others * & $27(7.2 \%)$ \\
\hline \multirow[t]{4}{*}{ Marital Status } & Single & $313(83.5 \%)$ \\
\hline & Married and together & $50(14.4 \%)$ \\
\hline & Divorced & $8(2.13 \%)$ \\
\hline & Others * & $4(1.1 \%)$ \\
\hline
\end{tabular}

\subsection{Characteristics of youths' families}


Regarding to youth families characteristics; from the total respondents, $36 \%$ were living with their friends/peer, followed by $33.86 \%$ living with both parents and the rest were either with father only or mother only. Regarding educational status of their parents, $36.5 \%$ of their fathers were secondary and above and maximum numbers of their mothers $(29.6 \%)$ were attended primary education. The higher proportion of the youths stated as they discussed sex related issues with their mothers $56.8 \%$ than they discussed with their fathers $36.8 \%$.Small number of the students $14.1 \%$ described as their family monthly expenditure $<=2000$ and majority of them described as $70.4 \%$ as monthly expenditures $2001-4000$ of their families.

Table 2

Characters of school youth students' families in Assosa Zone western Ethiopia, 2020.

\begin{tabular}{|c|c|c|}
\hline \multicolumn{2}{|l|}{ Characteristics $(n=375)$} & \multirow{2}{*}{$\begin{array}{l}\text { count and percentages } \\
86(22.9 \%)\end{array}$} \\
\hline Mother's education & Can't read and write & \\
\hline & Read \& write Only & $98(26.1 \%)$ \\
\hline & Primary school & $111(29.6 \%)$ \\
\hline & Secondary and above & $80(21.3 \%)$ \\
\hline \multirow[t]{4}{*}{ Father's education } & Can't read and write & $67(17.9 \%)$ \\
\hline & Read \& write Only & $137(36.5 \%)$ \\
\hline & Primary school & $55(14.7 \%)$ \\
\hline & Secondary and above & $116(30.9 \%)$ \\
\hline \multirow[t]{4}{*}{ Monthly expenditures by ETB } & $<=2000$ & $53(14.1 \%)$ \\
\hline & $2001-3000$ & $142(37.9 \%)$ \\
\hline & $3001-4000$ & $122(32.5 \%)$ \\
\hline & $<=4000$ & $58(15.5 \%)$ \\
\hline \multicolumn{3}{|c|}{ Did you discuss sex related issues with your father? } \\
\hline & yes & $138(36.8 \%)$ \\
\hline & no & $237(63.2 \%)$ \\
\hline \multicolumn{3}{|c|}{ Did you discuss sex related issues with your mother? } \\
\hline & yes & $213(56.8 \%)$ \\
\hline & No & $162(43.2 \%)$ \\
\hline
\end{tabular}

\subsection{Knowledge, attitudes towards SRH services and sexual practices}

All study participants were asked to select services they know provided under youth SRH and two hundred nineteen $58.4 \%$ and one hundred eighty $48 \%$ of them knows Voluntary counselling and testing of HIV and 
contraceptives/condom as service given under youth SRH services consecutively. The other less known components were Pregnancy test $11931.7 \%$ and One hundred ten $29.3 \%$ abortion services followed by the least known services was treatment of sexually transmitted infections by $9925.5 \%$ of youth students.

\subsection{Source of SRH information}

Two hundred fourteen $62.7 \%$ of the students knows STIs as HIV/AIDS only. Fifty five students $14.6 \%$ fail to state any sexual and reproductive health services. Friends and teachers were reported by $54.2 \%$ as time main source of information related to reproductive health services and posters $6.9 \%$ was the least .The majority of the participants eighty two (67.8\%) responds as private clinic as the likely place to receive SRH services followed by $24.8 \%$ as governmental health facilities. For the purpose of knowledge assessments out of six questions on SRH services with the score out of six with dichotomous forms yes or no response provided. One hundred fifty six (41.6\%) were knowledgeable and two hundred nineteen $58.4 \%$ were not knowledgeable of SRH service areas.

Regards to attitudes of youths towards SRH services six attitude questions with five liker scale from strongly agree to strongly disagree ranging from a minimum score of 6 to 30 maximum were provided. Two hundred fifty four $(67.7 \%)$ of the students have favourable attitude towards youths sexual and reproductive health services (32.3\%) have no favourable attitude. Majority of the participants agreed on the statements SRH service is important for youths; youths have a right.

Zone western Ethiopia, 2020.

\subsection{Sexual behaviours of participants}

Out of the 375 participants $26.4 \%$ of them already sexually initiated and the rest were not and $61,6 \%$ were premarital sexual practices .Due to different reasons more than fifty percept of $60(73.3 \%)$ them didn't use contraceptive during the first sexual events. Didn't perceive sexual and reproductive health problems $44.4 \%$,fear of family and community $35.4 \%$ and $20.2 \%$ of them missed due to unavailability of service facility near to living areas. The mean age of first sexual intercourse was at 14.5 with a standard deviation of 2.0 years.

\subsection{Youth preference of Place, time and health care provider}

Regarding to youth preferences of health facility SRH services, majority of the $66.1 \%$ prefer youth center and $5.9 \%$ of them prefers anywhere with privacy. In addition special service hour youth prefers was during the time when there is no more patients $360(96 \%)$ and usual working hours $3.7 \%$. Youths also prefers Health care providers for SRH services deviates to Young providers of the same sex $44.5 \%$, followed by Young and any sex were prefers $32.8 \%$ health care providers. 
Table 3

Youth preferences of place, time and health care providers in Assosa District west Ethiopia.

\begin{tabular}{|c|c|c|c|}
\hline \\
\hline \multicolumn{2}{|l|}{ Characteristics $(n=375$} & \multicolumn{2}{|c|}{ Percentages } \\
\hline \multirow[t]{4}{*}{ Service place preference } & Health Center with separate room & 35 & $(9.3 \%)$ \\
\hline & Youth center & 248 & $(66.1 \%)$ \\
\hline & In school health services & 72 & $(19.2 \%)$ \\
\hline & Anywhere with privacy & 20 & $(5.3 \%)$ \\
\hline \multirow[t]{2}{*}{ Time preferences } & Usual working hours & 15 & $(4 \%)$ \\
\hline & Special hour for youths & 360 & $(96 \%)$ \\
\hline \multirow[t]{4}{*}{ Provider preferences } & Young and the same sex & 167 & $(44.5 \%)$ \\
\hline & Young and any sex & 123 & $(32.8 \%)$ \\
\hline & Matured and the same sex & 69 & $(18.4 \%)$ \\
\hline & Matured and any sex & 14 & $(3.7 \%)$ \\
\hline
\end{tabular}

This study reveals that $32 \%$ [95\% $\mathrm{Cl}(26.9,36.8)]$ of the participants had utilized at least one component of sexual and reproductive health services in the past six months. The SRH service they received were SRH information, education andCounselling $22 \%$, contraceptive/ or condom $17.6 \%$, and the least service utilized was abortion services by $2 \%$ of students. The first place of SRH services utilized was private health facilities $51.2 \%$ followed by governmental health facilities $26.5 \%$ ), family guidance association $17.5 \%$ and $5 \%$ students respond that they utilized from traditional healers.

\subsection{Reasons of youth students not used SRH services}

The main reasons of youths not utilized SRH services were lack of separate room $21.3 \%$ and Judgmental attitude of health care providers $16.8 \%$, too young to get the services $12.2 \%$, no awareness of service $11.8 \%$, fear of parent $11 \%$,cost of service and commodities $7.1 \%$,inconvenient service location and lack of youth clinic $11.8 \%$, distance of the facility and inconvenient service hours $8.5 \%$ were common reasons of youths not utilized SRH services.

\subsection{Factors associated with use of Sexual and Reproductive Health Service}

The effects of different independent variables were tested for utilization of sexual and reproductive health services using logistic regression analysis. With an intention of controlling confounding effect, variables that were statistically significant with sexual reproductive health service utilization on bivariate analysis were interred in to multivariable in logistic regressions. 
During multivariate logistic analysis Age, discussion with mother, peer education, pocket money, and distance of the facility were significant. The likely hood of SRH service utilization was 2.74 times higher among age group of 20-24years than $15-19$ years ages [ $(95 \% \mathrm{Cl})$ AOR $=2.74(1.52,4.95)]$. Youths those discussed SRH issues with their mother were 2.78 more likely to utilize SRH services when compared to their counterparts $[(95 \% \mathrm{Cl}) \mathrm{AOR}=2.78(1.59,4.67)]$.Similarly those students participated in peer education were 2.27 times more likely to utilize SRH services than those who were not participated in peer education [(95\% Cl) AOR= $2.27(1.24,4.16)]$.

Table 4

Associated factors of SRH service utilizations among high school students in Assosa zone western Ethiopia, 2021.

\begin{tabular}{|c|c|c|c|c|c|c|}
\hline \multicolumn{2}{|c|}{ Variables $(n=375)$} & \multicolumn{2}{|c|}{ SRHs Utilization } & \multirow[t]{2}{*}{ COR $(95 \% \mathrm{Cl})$} & \multirow[t]{2}{*}{ AOR $(95 \% \mathrm{Cl})$} & \multirow[t]{2}{*}{ P-Val } \\
\hline & & Yes & No & & & \\
\hline \multirow[t]{2}{*}{ Students age } & $15-19$ & $41(27.5 \%)$ & $136(72.5 \%)$ & $1: 00$ & $1: 00$ & \\
\hline & $20-24$ & 79 (36\%) & $118(64 \%)$ & $2.12(1.35,3.3)$ & $\begin{array}{l}2.74(1.52, \\
4.95)\end{array}$ & 0.001 \\
\hline \multirow{4}{*}{$\begin{array}{l}\text { Level of } \\
\text { education }\end{array}$} & 9th & $53(28.5 \%)$ & 133(71.5\%) & $1: 00$ & $1: 00$ & \\
\hline & 10th & $36(26.3 \%$ & 101(73.7\%) & $0.89(0.42,3.5)$ & $0.82(0.61,4.25)$ & 0.35 \\
\hline & 11 th & $16(59.3 \%)$ & $11(40.7 \%)$ & $3.65(1.24,6.4)$ & $2.87(1.20,1.62)$ & 0.30 \\
\hline & 12th & $15(60 \%)$ & $10(40 \%)$ & $3.76(1.59,8.9)$ & $2.63(2.17,4.26)$ & 0.48 \\
\hline \multirow{2}{*}{$\begin{array}{l}\text { Discussion } \\
\text { with mother }\end{array}$} & yes & $74(45.6 \%)$ & $88(54.4 \%)$ & $3.05(1.94,4.7)$ & $2.78(1.59,4.67)$ & 0.001 \\
\hline & no & $46(21.6 \%)$ & 167(78.4\%) & $1: 00$ & $1: 00$ & \\
\hline \multirow{2}{*}{$\begin{array}{l}\text { Peer } \\
\text { education }\end{array}$} & yes & $51(49 \%)$ & $53(51 \%)$ & $2.81(1.75,4.5)$ & $2.27(1.24,4.16)$ & 0.008 \\
\hline & no & $69(25.5 \%)$ & $202(74.5 \%)$ & $1: 00$ & $1: 00$ & \\
\hline \multirow[t]{2}{*}{$\begin{array}{l}\text { Pocket } \\
\text { money }\end{array}$} & yes & $63(49.6 \%)$ & $64(50.4 \%)$ & $3.29(2.08,5.2)$ & $\begin{array}{l}2.81(2.35 \\
, 5.09)\end{array}$ & 0.001 \\
\hline & no & $57(23 \%)$ & 191(73\%) & $1: 00$ & $1: 00$ & \\
\hline \multirow[t]{2}{*}{$\begin{array}{l}\text { Knowledge } \\
\text { status }\end{array}$} & knowledgeable & $81(37 \%)$ & 138(67\%) & $1.76(1.11,2.7)$ & $\begin{array}{l}1.30(1.54 \\
.4 .73)\end{array}$ & 0.04 \\
\hline & $\begin{array}{l}\text { Not } \\
\text { knowledgeable }\end{array}$ & $39(25 \%)$ & $117(75 \%)$ & $1: 00$ & $1: 00$ & \\
\hline \multirow{2}{*}{$\begin{array}{l}\text { Ever had } \\
\text { sexual } \\
\text { intercourse }\end{array}$} & yes & $41(41.4 \%)$ & $58(58.6 \%)$ & $1.77(1.09,2.8)$ & $\begin{array}{l}\text { 1.82(1.25, } \\
3.26)\end{array}$ & 0.02 \\
\hline & no & $79(27.5 \%)$ & 197(72.5\%) & $1: 00$ & $1: 00$ & \\
\hline \multirow{2}{*}{$\begin{array}{l}\text { Service time } \\
\text { conveniences }\end{array}$} & yes & 77 (41\%) & 111 (59\%) & $2.32(1.48,3.6)$ & $1.42(0.77,2.6)$ & 0.25 \\
\hline & no & $43(22 \%)$ & 144 (78\%) & $1: 00$ & $1: 00$ & \\
\hline
\end{tabular}




\section{Discussion}

Utilization of sexual and reproductive health services among youth students of highs schools in Assosa zone was found to be $32 \%$ with $95 \% \mathrm{Cl}(26.9,36.8)$, elicited by asking the past six months use of SRH services before the date of data collection. This finding is similar with study done in Bahir Dar city Ethiopia had reported (24). The possible justifications for this similarity might be due to the educational level of participants and socio demographic characters. In other way report of this study is lower than the study done in Mekelle town North Ethiopia (25) which was $69.1 \%$ of youths used youth friendly services in the past one year.

On the other hand this finding is greater than study conducted in Nekemte town North east Ethiopia (21) which was $21.21 \%$, and in Machakel district 21.5\%, Northwest Ethiopia(36) of youth utilize SRH services. For these possible discrepancies, it might be due to differences in the availability and accessibility of youth friendly sexual and reproductive health facilities or the availability of youth canters, and/or difference in individual /socio-demographic characteristics of the study participants.

Youth within age groups of 20 to 24 years were 2.74 times more likely to utilize SRH services when compared to those with age of between 15 to $19[(95 \% \mathrm{Cl}) \mathrm{AOR}=2.74(1.52,4.95)$. This finding is in agreement with the study conducted in west wadawacho Hadiya Zone(37) but contrasted with the study done in North Showa zone in which less than 19 years were more utilized the service than those more than 20 years old(38). According to this study parental discussions was significantly associated with SRH service utilization; youths those discussed SRH issues with their mothers were 2.78 times more likely to use the services than those who never discussed $[(95 \% \mathrm{Cl}) \mathrm{AOR}=2.78(1.59,4.67)]$. This might be due to as parents had more knowledge of SRH services and freely discussed youths with their parents, they would have a better knowledge and awareness about SRH services and thus would motivate them to use the service. This finding was in line with two studies conducted in Awabel North west, Ethiopia and South west Oromia, Ethiopia(28, 30),But in contrast with this finding the study done in Goba Town, Southeast Ethiopia ;parental discussion was protective effects against utilization of youths SRH services (39). This might be due to the cultural diversity, norm and ethnical diversity of these study participants.

Peer education and knowledge status of SRH were significantly associated with utilization of SRH services. Those students ever participated in peer education were 2.27 times more likely to use SRH services than their counterparts[ $(95 \% \mathrm{Cl}) \mathrm{AOR}=2.27(1.24,4.16)]$. This is in line with the study conducted in Awabel North west Ethiopia (30).Possible explanation for this finding is youth preferred peer educators as a source of sexual and reproductive health information since they considered them knowledgeable and trust worthy. Similarly those who had knowledge of SRH were 1.3 times more likely to use SRH services than those who were not knowledge about SRH services $[(95 \% \mathrm{Cl}) \mathrm{AOR}=1.3(1.54,2.73)]$. This finding is in line with the two studies conducted in South Omo Zone southern Ethiopian and in Asgede-Tsimbla district Northern Ethiopia (40, 41).Possible explanation of this discrepancy is Still the observed proportion is not adequate to say youths are knowledgeable in sexual and reproductive service areas.

This study also identified that history of sexual initiation was significantly associated with SRH service utilization. In which the students those ever had sexual intercourse were 1.8 times more likely to utilize SRH 
services than their counter parts [(95\% Cl) AOR= 1.8(1.25,3.26)]. This is in line with the study done in Southwest Oromia, Ethiopia(28).Possible justification of this may be sexually active respondents were more exposed to SRH problems thus they were concerned about their sexual and reproductive heaths than responds those never sexually initiated.

Having pocket money also significant predictor of SRH service utilization in this study, Those had pocket money for daily expense were 2.8 time more likely to utilize SRH service than those had no pocket money $[(95 \% \mathrm{Cl}) \mathrm{AOR}=2.81(2.35,5.09)]$. This finding is in line with the study conducted in Woreta town, North West Ethiopia(32).The possible explanation of this association is, since sexual and reproductive health problems necessitates privacy thus youths with pocket money can use services like treatments of STI and condoms without asking help from others.

\section{Limitations of the study}

Since this study examines personal and sensitive issues, obtaining honest responses among youth students might have been difficult. Therefore researchers better focus on qualitative study on such sensitive study.

\section{Conclusions}

This study identified that utilization of sexual and reproductive health services was low

to achieve 2016 strategies of Ethiopian ministry of health developed on youth's reproductive health. Youths who had pocket money for daily expense, had a parental discussion on sexual and reproductive health issues, peer education and knowledge status ofyouth on sexual and reproductive health services were predictors of youth sexual and reproductive health service utilization.

\section{Abbreviations}

OR: odds ratio; Cl: confidence interval; NOS: Newcastle-Ottawa Quality Assessment Scale; SNNPR: Southern Nations Nationalities and People Region; AIDS: Acquired immunodeficiency syndromes; AY: Adolescence and Youth; EDHs: Ethiopian Demographic and Health Survey; YSRH: youth sexual and reproductive health; WHO: World Health Organization.

\section{Declarations}

\section{Acknowledgement}

My deepest gratitude goes to college of health science, Bahirdar University for giving me opportunity to do this study. Next I want to extend my deepest gratitude for Mr Getahun Fetensa Assistant professor of Wollega University and Tamesgen Teshome for their great advising and Finally, I want to thank all those who support me from the beginning up to the end of this study. It is because of all this study becomes evident. 
1. Hunduma Dina: - Developing proposal, analysis, and interpretation of the result, manuscript writing and summation.

2. Simachew Kassa:-Proposal evaluation, analysis and interpretation of the results

3. Shumiye Shiferaw :- Proposal evaluation, interpretation of the results and support me manuscript preparation

All the authors read and approved the final manuscript

\section{Funding information}

There was no funding source for this study

\section{Availability of data and materials}

The datasets used and/or analysed during the current study available from the corresponding author on reasonable request.

\section{Ethics approval and consent to participate}

Not applicable.

\section{Consent for publication}

Not applicable.

\section{Competing interests}

The authors declare that they have no competing interests.

\section{References}

1. African Population and Health Research Center (APHRC). Protecting in-School Adolescents from HIV/ AIDS, STIs and Unwanted Pregnancy: Evidence-based Lessons for Programs and Policy. Policy BriefNo.11, 2009.

2. Hervish A, Clifton D. Status report: Adolescents and young people in sub-Saharan Africa. Opportunities and challenges. 2012.

3. UNFPA W. UNAIDS,'Position statement on condoms and the prevention of HIV, other sexually transmitted infections and unintended pregnancy', 2015. 2016.

4. The World Bank Group. Why invest in Children and Youth. NewYork: World Bank; 2011. Ref Type: Online Source.

5. Chen XK, Wen SW, Fleming N, Demissie K, Rhoads GG, Walker M. Teenage pregnancy and adverse birth outcomes: a large population based retrospective cohort study.Int J Epidemiol 2007;36(2):368-73.

6. Ministry of Health [Ethiopia]. Standards on Youth Friendly Reproductive Health Services Service Delivery Guideline \& Minimum Service Delivery Package on YFRH Services. Addis Ababa; 2008. 
7. Organization WH. WHO meeting on ethical, legal, human rights and social accountability implications of self-care interventions for sexual and reproductive health, 12-14 March 2018, Brocher Foundation, Hermance, Switzerland: summary report. World Health Organization, 2018.

8. UNFPA W. UNAIDS,'Position statement on condoms and the prevention of HIV, other sexually transmitted infections and unintended pregnancy', 2016.

9. Sherwood J, Sharp A, Cooper B, Roose-Snyder B, Blumenthal S. HIV/AIDS National Strategic Plans of Sub-Saharan African countries: an analysis for gender equality and sex-disaggregated HIV targets. Health policy and planning. 2017;32(10):1361-7.

10. Central Statistical Agency (CSA) [Ethiopia] and ICF. Ethiopia Demographic and Health Survey 2016. Addis Ababa, Ethiopia, and Rockville, Maryland, USA: CSA and ICF. 2016.

11. Ministry of Women, Children, and Youth Affairs. Ethiopia Adolescent and Youth Status Report, 2014. Addis Ababa, Ethiopia.

12. Jain A, Ismail H, Tobey E, Erulkar A. Understanding adolescent and youth sexual and reproductive healthseeking behaviors in Ethiopia: implications for youth friendly service programming. 2017.

13. Mekonnen Y, Telake DS, Wolde E. Adolescent childbearing trends and sub-national variations in Ethiopia: a pooled analysis of data from six surveys. BMC pregnancy and childbirth. 2018;18(1):276.

14. Sedgh G, Finer L, Bankole A, Eilers $M$, Singh S. Adolescent pregnancy, birth, and abortion rates across countries: levels and recent trends. J Adolesc Health.2015;56(2):223-30.

15. Kassie BA, Yenus H, Berhe R, Kassahun EA. Prevalence of sexually transmitted infections and associated factors among the University of Gondar students, Northwest Ethiopia: a cross-sectional study. Reproductive health. 2019;16(1):163.

16. Say L, Chou D, Gemmill A, Tuncalp O, Moller AB, Daniels J, Gulmezoglu AM,Temmerman M, Alkema L. Global causes of maternal death: a WHO systematic analysis. Lancet Glob Health. 2014;2(6):e323-33.

17. Abdissa B, Aklilu A, Admasu E, Girma S. Knowledge of Safe Abortion and Associated Factors among Female Students in Debre Markos University, Amhara Regional State, Northwest Ethiopia, 2016: A Cross Sectional Study. Int J Womens Health Wellness. 2019;5(100):2474-1353.

18. Wodajo LT, Mengesha ST, Beyen TK. Unsafe abortion and associated factors among women in reproductive age group in Arsi Zone, Central Ethiopia. International Journal of Nursing and Midwifery. 2017;9(10):121-8.

19. Ministry of Education (MOE) [Ethiopia]. Higher Educational institutions partnership forum, HIV/AIDS and SRH communication strategy for higher education institutions. Addis Ababa, Ethiopia. 2013.

20. Oljira L. Ministry of Health [Ethiopia]. National adolescent and youth reproductive health strategy 20162020. Addis Ababa: Federal Democratic Republic of Ethiopia, Ministry of Health.2016.

21. Binu W, Marama T, Gerbaba M, Sinaga M. Sexual and reproductive health services utilization and associated factors among secondary school students in Nekemte town, Ethiopia. Reproductive health. 2018;15(1):64.

22. Dapaah JM, Appiah SCY, Badu E, Obeng B, Ampiah V. Does Facility Based Sexual and Reproductive Health Services Meet the Needs of Young Persons? Views from Cross Section of Ghanaian Youth. 2015. 
23. Malawi Ministy of helath(MMOH). National Youth Friendly Health Services Strategy 2015-2020.Republic Of Malawi.2015.

24. Abebe M, Awoke W. Utilization of youth reproductive health services and associated factors among high school students in Bahir Dar, Amhara regional state, Ethiopia. Open Journal of Epidemiology. 2014;4(02):69.

25. Kahsay K, Berhe S, Alemayehu M. Utilization of youth friendly services and associated factors in Mekelle Town, Tigray, Northern Ethiopia. 2016.

26. Motuma A, Syre T, Egata G, Kenay A. Utilization of youth friendly services and associated factors among youth in Harar town, east Ethiopia: a mixed method study. BMC health services research. 2016;16(1):272.

27. Bilal SM, Spigt M, Dinant GJ, Blanco R. Utilization of Sexual and Reproductive Health Services in Ethiopia-Does it affect sexual activity among high school students? Sexual \& Reproductive Healthcare. 2015;6(1):14-8.

28. Birhanu Z, Tushune K, Jebena MG. Sexual and Reproductive Health Services Use, Perceptions, and Barriers among Young People in Southwest Oromia, Ethiopia. Ethiopian journal of health sciences. 2018;28(1):37-48.

29. Helamo D, Kusheta S, Bancha B, Habtu Y, Yohannes S. Utilization and factors affecting adolescents and youth friendly reproductive health services among secondary school students in Hadiya zone, Southern Nations, Nationalities and Peoples Region, Ethiopia. Int J Pub Health Safe. 2017;2(141):2.

30. Ayehu A, Kassaw T, Hailu G. Level of young people sexual and reproductive health service utilization and its associated factors among young people in Awabel District, Northwest Ethiopia. PloS one. 2016;11(3).

31. Frohlich JA, Mkhize N, Dellar RC, Mahlase G, Montague CT, Abdool Karim Q. Meeting the sexual and reproductive health needs of high-school students in South Africa: experiences from rural KwaZulu-Natal. South African medical journal = Suid-Afrikaanse tydskrif vir geneeskunde. 2014;104(10):687-90.

32. Abate AT, Ayisa AA. Reproductive health services utilization and its associated factors among secondary school youths in Woreta town, South Gondar, North West Ethiopia: a cross sectional study. BMC research notes. 2019;12(1):90.

33. (2019) Assosa zone Administration health burueau and educational bureau. 2019 Annual Report (Unpublished).

34. Habtu Y, Helamo D. Utilization and Factors Affecting Adolescents and Youth Friendly Reproductive Health Services among Secondary School Students in Hadiya Zone, Southern Nations, Nationalities and Peoples Region, Ethiopia. 2018 02/16;2.

35. Tlaye KG, Belete MA, Demelew TM, Getu MA, Astawesegn FH. Reproductive health services utilization and its associated factors among adolescents in Debre Berhan town, Central Ethiopia: a communitybased cross-sectional study. Reproductive health. 2018 Dec 27;15(1):217. PubMed PMID: 30587220. Pubmed Central PMCID: PMC6307180. Epub 2018/12/28. eng.

36. Amanuel A, Assefa S: Reproductive Health Knowledge and Services Utilization among Rural Adolescents in Machakal district, Northwest Ethiopia. Asian Journal of Pharmacy, Nursing and Medical Sciences. June 2013 01(01);25-37. 
37. Cherie N, Tura G, Aderajew NT. Reproductive health needs and service utilization among youths in West Badewacho Woreda, Hadiya Zone, South Ethiopia. Journal of public health and epidemiology. 2015;7(4):145-53.

38. Negash W, Dessalegn M, Yitayew B, Demsie M, Wagnew M, Nyagero J. Reproductive health service utilization and associated factors: the case of north Shewa zone youth, Amhara region, Ethiopia. The Pan African medical journal. 2016;25(Suppl 2).

39. Gebreselassie B, Takele A, Bililign N, Adera A, Ayene Y, Woreta A, et al. Assessment of Reproductive Health Service Utilization and Associated Factors Among Adolescents (15-19 Years Old) in Goba Town. Southeast Ethiopia. 2015;3(4):203-12.

40. Haile B, Shegaze M, Feleke T, Glagn M, Andarge E. Disparities in utilization of sexual and reproductive health services among high school adolescents from youth friendly service implemented and nonimplemented areas of South Ari district, South Omo zone, Southern Ethiopia: a comparative crosssectional study. 2020.

41. Gebreyesus $H$, Teweldemedhin M, Mamo A. Determinants of reproductive health services utilization among rural female adolescents in Asgede-Tsimbla district Northern Ethiopia: a community based crosssectional study. Reproductive health. 2019 Jan 11;16(1):4. PubMed PMID: 30634991. Pubmed Central PMCID: PMC6330493. Epub 2019/01/13. eng.

\section{Figures}

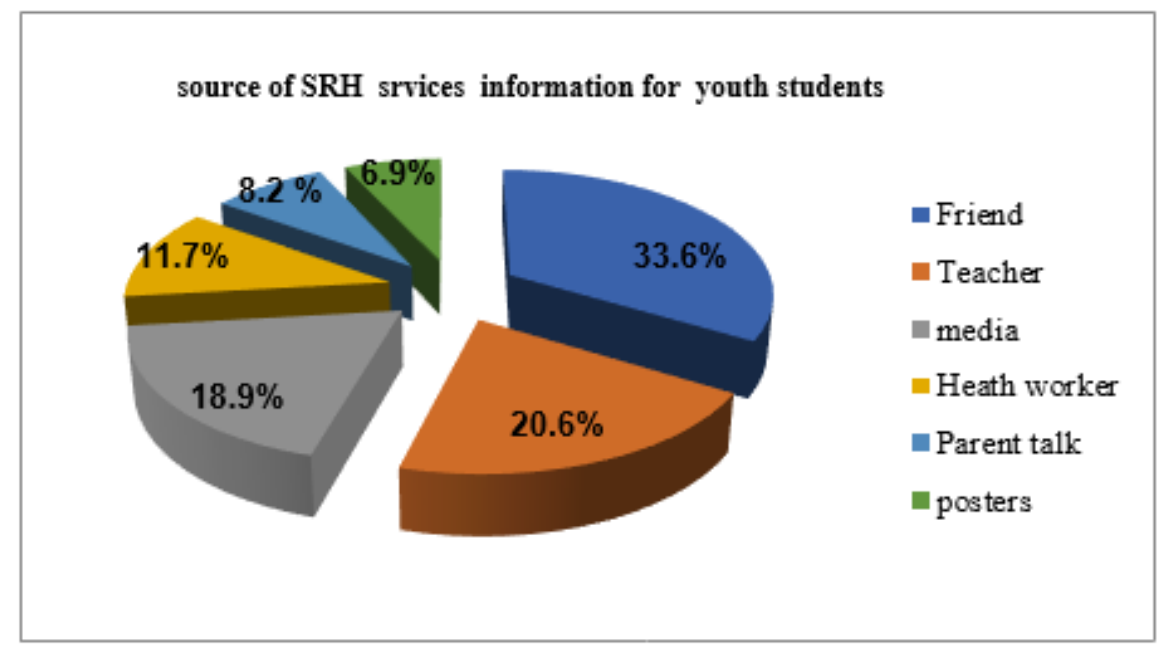

\section{Figure 1}

Sources of SRH services information for high school youth students in Assosa Zone western Ethiopia, 2020. 


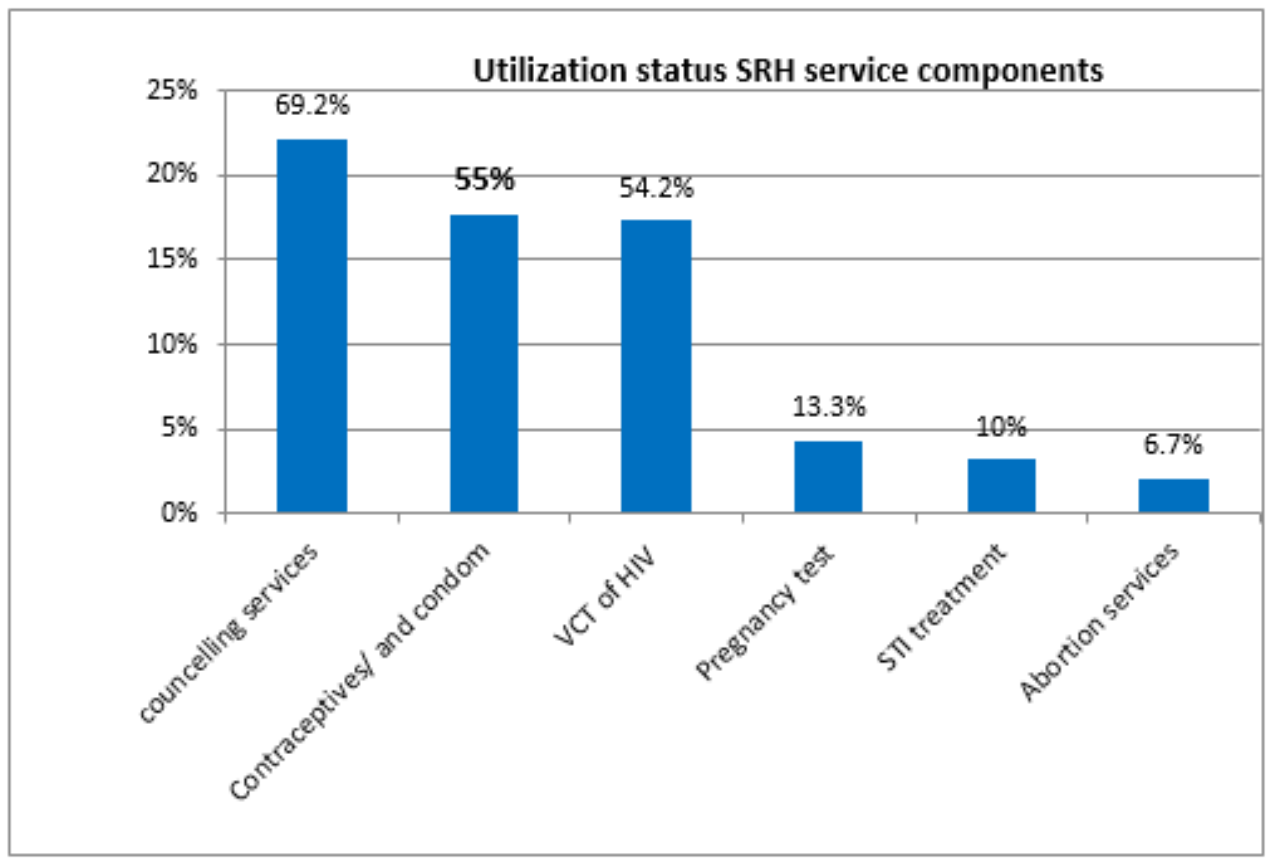

\section{Figure 2}

Utilization status of SRH services among high school youth students in Assosa zone west Ethiopia, 2020. N.B:-Due to multiple responses; Summation of each type might be more than 100 percent or might be less than $100 \%$ due to missed values.

\section{Supplementary Files}

This is a list of supplementary files associated with this preprint. Click to download.

- QuestENGversion.docx 